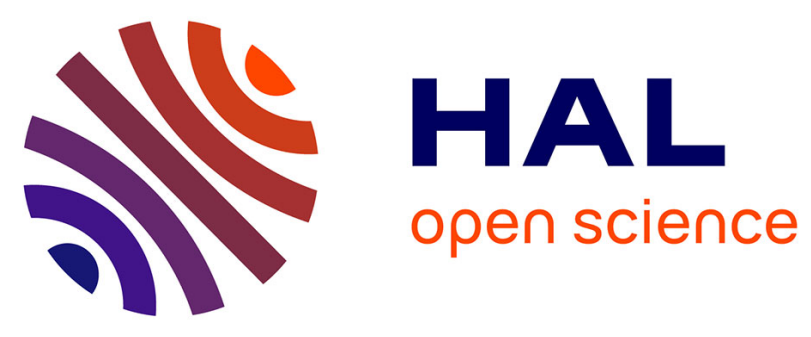

\title{
Interplay between Polymer Chain Conformation and Nanoparticles Assembly in Model Industrial Silica/Rubber Nanocomposites
}

\author{
Adrien Bouty, Laurent Petitjean, Julien Chatard, Rachid Matmour, \\ Christophe Degrandcourt, Ralf Schweins, Florian Meneau, Pawel \\ Kwasńiewski, François Boué, Marc Couty, et al.
}

\section{To cite this version:}

Adrien Bouty, Laurent Petitjean, Julien Chatard, Rachid Matmour, Christophe Degrandcourt, et al.. Interplay between Polymer Chain Conformation and Nanoparticles Assembly in Model Industrial Silica/Rubber Nanocomposites. Faraday Discussions, 2016, 186, pp.325-343. 10.1039/C5FD00130G . hal-01389908

\section{HAL Id: hal-01389908 https://hal.science/hal-01389908}

Submitted on 30 Oct 2016

HAL is a multi-disciplinary open access archive for the deposit and dissemination of scientific research documents, whether they are published or not. The documents may come from teaching and research institutions in France or abroad, or from public or private research centers.
L'archive ouverte pluridisciplinaire HAL, est destinée au dépôt et à la diffusion de documents scientifiques de niveau recherche, publiés ou non, émanant des établissements d'enseignement et de recherche français ou étrangers, des laboratoires publics ou privés. 


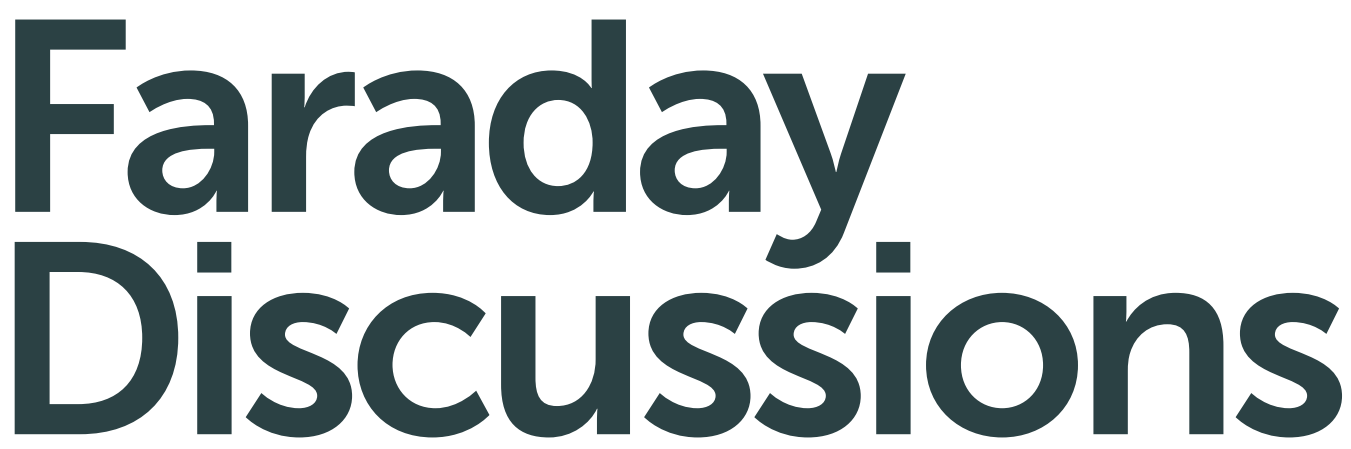

\section{Accepted Manuscript}

This manuscript will be presented and discussed at a forthcoming Faraday Discussion meeting.

All delegates can contribute to the discussion which will be included in the final volume.

Register now to attend! Full details of all upcoming meetings: http://rsc.li/fd-upcoming-meetings

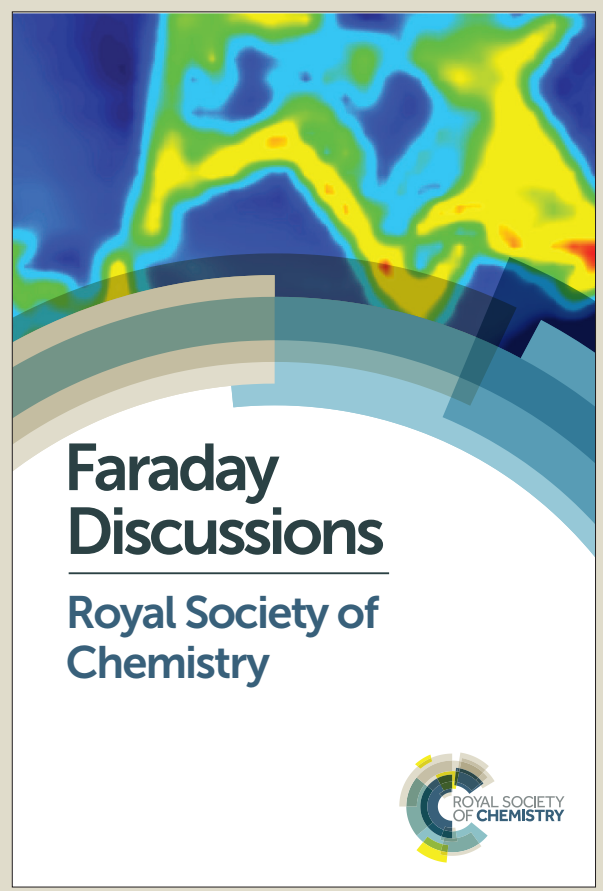

This is an Accepted Manuscript, which has been through the Royal Society of Chemistry peer review process and has been accepted for publication.

Accepted Manuscripts are published online shortly after acceptance, before technical editing, formatting and proof reading. Using this free service, authors can make their results available to the community, in citable form, before we publish the edited article. We will replace this Accepted Manuscript with the edited and formatted Advance Article as soon as it is available.

You can find more information about Accepted Manuscripts in the Information for Authors.

Please note that technical editing may introduce minor changes to the text and/or graphics, which may alter content. The journal's standard Terms \& Conditions and the Ethical guidelines still apply. In no event shall the Royal Society of Chemistry be held responsible for any errors or omissions in this Accepted Manuscript or any consequences arising from the use of any information it contains.

This article can be cited before page numbers have been issued, to do this please use: A. Bouty, L. Petitjean, J. Chatard, R. Matmour, C. Degrandcourt, R. Schweins, F. Meneau, P. Kwaniewski, F. Boué, M. Couty and J. Jestin, Faraday Discuss., 2015, DOI: 10.1039/C5FD00130G. 


\section{Interplay between Polymer Chain Conformation aand}

\section{Nanoparticles Assembly in Model Industrial}

\section{Silica/Rubber Nanocomposites}

Adrien Bouty ${ }^{a, b}$, Laurent Petitjean ${ }^{b}$, Julien Chatard ${ }^{b}$, Rachid Matmour ${ }^{b}$, Christophe Degrandcourt ${ }^{b}$, Ralf Schweins $^{c}$, Florian Meneau $^{d}$, Pawet Kwasńiewski ${ }^{e}$, François Boué ${ }^{a}$, Marc Couty ${ }^{b}$ and Jacques $\operatorname{Jestin}^{a^{*}}$

${ }^{a}$ Laboratoire Léon Brillouin, CEA Saclay 91191 Gif-sur-Yvette Cedex France

${ }^{\mathrm{b}}$ Manufacture Française des Pneumatiques MICHELIN, Site de Ladoux, 23 place des Carmes Déchaux, F-63 040 Clermont-Ferrand, Cedex 9, France

${ }^{\mathrm{c}}$ Institut Laue-Langevin, BP 156, 6, rue Jules Horowitz, 38042 Grenoble Cedex 9, France

d Synchrotron SOLEIL, L'Orme des Merisiers, PO Box 48, Saint-Aubin, 91192 Gif/Yvette, France

${ }^{\mathrm{e}}$ European Synchrotron Radiation Facility, 6 rue Jules Horowitz 38043 Grenoble, France

\footnotetext{
* Corresponding authors: jacques.jestin@cea.fr
} 
The question of the influence of nanoparticles (NP) on chain dimensions in polymer nanocomposites (PNC) has been treated mainly through the fundamental way using theoretical or simulation tools and experiments on well-defined model PNC. Here we present the first experimental study about the influence of NP on the polymer chain conformation for PNC designed to be as close as possible to industrial systems employed in tire industry. PNC are silica nanoparticles dispersed into a StyreneButadiene-Rubber (SBR) matrix whose NP dispersion can be managed by NP loading with interfacial coating or coupling additives usually employed in the manufacturing mixing process. We associated specific chain (d) labeling, and the so-called Zero Average Contrast (ZAC) method, with SANS, in-situ SANS and SAXS/TEM experiments to extract the polymer chain scattering signal at rest for non-cross linked and under stretching for cross-linked PNCs. NP loading, individual clusters or connected network, as well as the influence of the type, the quantity of interfacial agent and the influence of the elongation rate have been evaluated on the chain conformation and on its related deformation. We clearly distinguish the situations where the silica is perfectly matched from the unperfected matching by direct comparison of SANS and SAXS structure factor. Whatever the silica matching situation, the additive type and quantity and the filler content, there is no thus significant change in the polymer dimension for NP loading up to $15 \% \mathrm{v} / \mathrm{v}$ within a range of $5 \%$. One can see an extra scattering contribution at low Q, as often encountered, enhanced for non-perfect silica matching but also visible for perfect filler matching. This contribution can be qualitatively attributed to specific $\mathrm{h}$ or $\mathrm{d}$ chains adsorption onto the NP surface inside the NP cluster that modifying the average scattering neutron contrast of the silica cluster. Under elongation, NP act as additional cross-linking junction preventing chain relaxation giving a deformation of the chain with NP closer to theoretical phantom network prediction than for pure matrix. 


\section{Introduction}

Progress in the understanding of the mechanisms that govern reinforcement of polymer matrices by NP is of a strategic interest to improve the design and the industrial processes of conception of new materials, specifically in tires industries. One of the critical breakthroughs is to be able to understand and describe the local structure of the filler (individual dispersion, connected network, aggregates or agglomerates...) as well as the one of the polymer chain (unmodified, stretched or compressed...) and to correlate them with the macroscopic mechanical behaviors of the materials like reinforcement, flow behavior or non-linear deformation [1,2]. Despite of the lack of a general model to describe the filler contribution (NP or assembly of NP), many progresses have been performed recently especially to dissociate the filler-filler interactions from the filler-matrix ones in reinforcement on both well-defined model [3-11] and simplified industrial systems [12-18]. On the contrary, the question of the matrix chain conformation and its modification due to the presence of NP has been, up to now, only addressed from a fundamental point of view. Theories have been developed using mainly simulations [19-25] considering the polymer radius of gyration $\mathrm{R}_{\mathrm{g}}$ and the NP radius $\mathrm{R}_{\mathrm{p}}$ ratio $\left(\mathrm{R}_{\mathrm{g}} / \mathrm{R}_{\mathrm{p}}\right)$. They lead to contradictory conclusions, either swelling or decreasing of $\mathrm{R}_{\mathrm{g}}$ as a function of the NP volume fraction, mostly when the polymer radius of gyration $\mathrm{R}_{\mathrm{g}}$ is equal or superior to the NP radius $\mathrm{R}_{\mathrm{p}}$. For example, Termonia et al. and Sung et al. $[19,20]$ reported a significant swelling of the chains for $R_{g} / R_{p}>1$ while Vacatello et al. [21, 22] reported a contraction of the chains. Sharaf et al. [23] have reported a swelling of the chain but for $\mathrm{R}_{\mathrm{g}} / \mathrm{R}_{\mathrm{p}}<1$. The situation has been also probed from an experimental view on welldefined model systems [26-34] using SANS and conventional polymers for which the labeling (d) forms can be conventionally accessible. These studies also yield controveral behaviors whose origins can be discussed according to different issues. A first possible origin is the difficulty to extract the experimental signal of the chain without ambiguous matching or undefined extra scattering. Nakatani et al. [26], Mackay et al. [27] (for the C60/PS system) and also Botti et al. [28] extracted the conformation of the polymer chain from a complex scattering signal in which the interactions between labeled (d) and 
non-labeled (h) chains have to be taken into account. Sen et al. [29], Nusser et al. [30] andiefrenixereteal. [31] (on latex/silica systems) used ZAC method, which cancels inter and intra-chains correlations, under unperfected matching conditions $[29,30]$ or in the presence of extra scattering signal coming from chain diffusion [31]. Jouault et al. [32] have demonstrated with a random (h/d) matrix who's matched the silica NP the unambiguous validity of the ZAC method while also observing an unresolved extra scattering contribution. An unambiguous contrast matched method used is also the one of Tuteja et al. [33] with cross-linked PS particles as fillers but concerns a very specific case of PNCs filled with soft fillers. Another contribution comes from the role played by the NP dispersion into the polymer matrix. Despite of the general prediction proposed by Mackay et al. [27] that suggested that the particle dispersion is only governed by the $\mathrm{R}_{\mathrm{g}} / \mathrm{R}_{\mathrm{p}}$ ratio, it has been also demonstrated that the particle dispersion strongly depend on the processing conditions [7,34]. Indeed, some of the previous studies suffer from a clear NP dispersion characterization that can render a confusing reading of the results if NPs are aggregated or form connected network. When reducing the discussion to the specific case for which the polymer radius of gyration is close to the NP radius, the situation is however relatively clear when most of the experiments have concluded that the chain conformation seems to be unaffected by the NPs [27, $28,29,31,32,33]$. Only two references [26, 30] show some effects that arise only at high NP loading, up to $40 \% \mathrm{v} / \mathrm{v}$. The absence of NP influence has been also confirmed recently by Crawford et al. [35] for PNCs with uniformly dispersed NPs. The previous examples examine the possible pre-strain of the chain induced by the NP. Another relevant contribution is to see whether the chain deformation is also affected by the NP under non-linear (large) deformations. This point has been addressed with simulations [36] or with indirect experiments like NMR [37]. A few experiments have probed the chain deformation scattering signal directly in presence of NP [38-40] on model PNC. Homogeneous overstrain has been established in triblock copolymer micelles of PI-PS-PI in cross-linked polyisoprene (PI) matrix where no overstrain effect have been measured in uncross-linked model silica/polystyrene PNC [40]. 
Beyond the fundamental interest of the previous studies mainly performed on modelviesystemplinthe question of the chain conformation inside a composite is also a main preoccupation of industrial actors. In the current context of petroleum resources depletion, a new challenge of the tire industry is to develop new materials that can reduce the oil consumption well as the $\mathrm{CO}_{2}$ emission while offering high mechanical performances (reinforcement, adhesion, tensile strength...). One possible way is to act on the NP, for example, by changing the classical carbon black filler by silica nanoparticles. Another possible way is to act on the rubber matrix by modifying the chain characteristics (molecular mass, polydispersity index, chemical functions...) to play with the polymer-NP interactions. Consequently, the question of the matrix chain conformation/deformation modification in PNC and its correlation with the mechanical performances of the material becomes a central question that we have addressed in the present paper.

We present here a complete study of model industrial silica/SBR systems using complementary SAXS/SANS/TEM experiments. We have previously demonstrated [18] that the silica NP dispersion can be controlled with coating (Octyltriethoxysilane - OCTEO) and coupling (Sulfurfunctional organosilane bis(triethoxysilyl)propyl tetrasulfide - Si69) additives into SBR for non-cross-linked PNCs similarly whatever the way of the sample preparation, solvent casting or internal mixing. Thanks to covalent bonds with the chains of the matrix, the coupling agent gives rise to smaller and denser aggregates than can form an interpenetrated percolating network when increasing the NP loading. The coating agent has a more repulsive action that reduce the network density. In other words, it is demonstrated that interfacial additives can tune the matrix chains confinement and appears thus to be a relevant way, as well as the NP loading, to evaluate the effect on the chain conformation. The synthesis of (d) labelled chain, restricted to low molecular mass, limits the capacity here to probe a broad range of NP dispersion leads to treat the case of NP organized as clusters. We varied the type and the quantity of interfacial additives for different NP loading from 1 to $15 \%$ vol. We applied the principle of ZAC by mixing labelled (d) and non-labelled (h) SBR chains to extract the single chain scattering signal and see whether or not the NP are potentially inducing some pre-straining effect on the chains. Clustering of NP 
is evaluated from SAXS/TEM analysis. To evaluate the effect of NP on the chain deformationicaplarge non-linear elongation rate, we completed the study with in-situ SANS measurements on cross-linked silica NP/SBR PNCs for different elongation rates.

\section{Material and methods}

\section{II.1. Synthesis of the (d) SBR chains}

d8-Styrene and d6-butadiene deuterated monomers were supplied by Cortectnet (purity of 99\%) and Eurisotop (purity of 99\%), respectively. Before their use for copolymerization, the monomers were first dried over BuLi for d6-butadiene and over calcium hydride and dibutyl magnesium for d8-styrene and then distilled to get the purified monomers. Similarly to hydrogenated SBR copolymers in classical runs, the deuterated SBR copolymer samples were synthesized by anionic polymerization by the Michelin Company. The copolymerization was initiated by BuLi in cyclohexane at $50^{\circ} \mathrm{C}$. Deuterated monomers were mixed in appropriate conditions to reach a microstructure as close as possible to the one of the hydrogenated chains used here $\left(26 \% \mathrm{wt}\right.$. of Styrene, $74 \% \mathrm{wt}$. of Butadiene; $\mathrm{M}_{\mathrm{n}}=40.000 \mathrm{~g} / \mathrm{mol}$, $\mathrm{M}_{\mathrm{w}}=41.700 \mathrm{~g} / \mathrm{mol}$, PDI =1.05). Two samples of deuterated SBR copolymers were obtained with the same microstructure as the hydrogenated ones (26\%wt. of Styrene, $74 \%$ wt. of Butadiene) and satisfying enough chain mass distribution Batch $1: \mathrm{M}_{\mathrm{n}}=49700 \mathrm{~g} / \mathrm{mol}_{\mathrm{w}} \mathrm{M}_{\mathrm{w}}=100500 \mathrm{~g} / \mathrm{mol}$, PDI =2.0, Batch 2 : $\mathrm{M}_{\mathrm{n}}=45000 \mathrm{~g} / \mathrm{mol}, \mathrm{M}_{\mathrm{w}}=96.270 \mathrm{~g} / \mathrm{mol}, \mathrm{PDI}=2.1$ ). The large polydispersities (PDI $\geq 2.0$ ) obtained for the deuterated copolymers is due to the presence of butene derivatives impurities present in nonnegligible quantities in the supplied deuterated butadiene. 
The matrix consists systematically in a mixture of chains from the hydrogenated and the deuterated batches, in the appropriate volume proportions to match the silica. Considering the neutron scattering length densities of the three components $\left(\rho_{\mathrm{SiO} 2}=3.4110^{10} \mathrm{~cm}^{-2}, \rho_{\mathrm{h}-\mathrm{SBR}}=0.5910^{10} \mathrm{~cm}^{-2}\right.$ and $\rho_{\mathrm{d}-\mathrm{SBR}}=6.67$ $10^{10} \mathrm{~cm}^{-2}$ ), the matrix composition is fixed to $54 \% \mathrm{v} . \mathrm{h}-\mathrm{SBR}+46 \% \mathrm{v}$. d-SBR as it theoretically matches silica. All samples were prepared by solvent casting route with Dimethylacetamide (DMAc) as solvent. The filler is Ludox type colloidal silica supplied by Aldrich (LS-30); the size distribution of these nanoparticles was finely characterized by SANS and gives a mean particle radius $\mathrm{R}_{0}=7.8 \mathrm{~nm}$ with a lognormal distribution of 0.15 .

The uncross-linked samples were synthesized with deuterated chains from Batch 1. The steps and conditions of this synthesis - Ludox transfer from water to DMAc, dissolution of matrix, addition of Ludox/DMAc suspension at $130^{\circ} \mathrm{C}$, solvent casting under nitrogen flow at $130^{\circ} \mathrm{C}$ - were precisely explained in a previous paper [18] and rigorously reproduced here for uncross-linked samples. Dispersing agents, coating (OCTEO) and coupling (Si69) additives are in a liquid form at room temperature. They are diluted at $7 \% \mathrm{v} / \mathrm{v}$ in methanol $(\mathrm{MeOH})$, and this solution is then introduced in the Ludox-DMAc suspension in the nominal quantity of 1 or 4 triethoxysilane groups per $\mathrm{nm}^{2}$ of silica for OCTEO and 1/2 or 1 triethoxysilane groups per $\mathrm{nm}^{2}$ of silica for Si69. Quantities were only adapted to both the small amount of Batch 1 and the following SANS experiment conditions (beam size). Uncrosslinked samples consist in malleable bulks of about 50mg, which can be fixed in a calibrated cell.

Cross-linked samples were synthesized with deuterated chains from Batch 2. The modifications relative to uncross-linked samples are the following. Five minutes before starting the casting phase, a crosslinking mixture is added in the polymer/silica/DMAc mixture at $130^{\circ} \mathrm{C}$ : soluble sulfur as cross-linker (2\%wt. with matrix) and CBS as vulcanization accelerator (2\%wt. with matrix). These cross-linking agents are fine powder under normal conditions, and their solubility was previously checked in pure DMAc at $130^{\circ} \mathrm{C}$. In the following phase, mixtures are poured into round Teflon molds (diameter $=$ 
$50 \mathrm{~mm}$, thickness $=10 \mathrm{~mm}$ ) and let cast in an oven at constant temperature $\mathrm{T}_{\text {Cast }}=130^{\circ} \mathrm{C}$ unidertiniterögen flow for 4 hours. During this phase both solvent casting and crosslinking are taking place. This yields dry films of about $1 \mathrm{~mm}$ of thickness, which do not creep at rest and under moderate traction.

\section{Small Angles Neutron Scattering SANS}

The composition of the matrix in all samples $(54 \% \mathrm{v}$. H-SBR $+46 \% \mathrm{v}$. D-SBR) is supposed to reach the Zero Average Contrast condition in SANS experiments. In this case, the scattering is directly proportional to the form factor of a single chain. SANS measurements in ZAC condition were performed on two spectrometers. Uncross-linked systems were measured at rest at the Laboratoire Léon Brillouin (LLB Saclay) on the spectrometer PAXE, by varying the wavelength $\lambda$ and the sample-todetector distance $\mathrm{D}$. The three configurations defined by $\lambda=4 \AA / \mathrm{D}=1 \mathrm{~m}, \lambda=6 \AA / \mathrm{D}=5 \mathrm{~m}$ and $\lambda=17 \AA$ / D $=5 \mathrm{~m}$, cover a total Q-range from $310^{-3}$ to $510^{-1} \AA^{-1}$. Samples were measured in calibrated quartz cells. The 2D patterns were reduced to $1 \mathrm{D}$ spectra $\mathrm{I}(\mathrm{Q})$ after radial averaging around the center of scattering. Standard corrections by sample thickness, neutron beam transmission, empty cell signal subtraction, detector efficiency, subtraction of incoherent scattering were applied to get the scattered intensities on absolute scale. Cross-linked systems were measured at the Institue Laue Langevin (ILL Grenoble) on the spectrometer D11. The three configurations defined by $\lambda=8 \AA / \mathrm{D}=1,2 \mathrm{~m}, \lambda=8 \AA / \mathrm{D}$ $=5 \mathrm{~m}$ and $\lambda=8 \AA / \mathrm{D}=20 \mathrm{~m}$ cover a total Q-range from $310^{-3}$ to $410^{-1} \AA^{-1}$. Samples were fixed in a home-made traction device allowing to perform measurements at fixed traction rate $\zeta=\mathrm{L} / \mathrm{L}_{0}$, ranging from 1 (sample at rest) to 1.8 . The resulting 2D SANS patterns were anisotropic and radially averaged in $30^{\circ}$ degree sectors along the parallel and the perpendicular direction of stretching. 


\section{Small Angles X-ray Scattering SAXS and Ultra Small Angles X-rays Scattering USAXY Urticle Online}

In SAXS experiments, we measure in filled systems the silica scattering due to the electronic contrast existing between SBR and silica: the scattering length densities are respectively $\rho_{\mathrm{SBR}}=8.4110^{10} \mathrm{~cm}^{-2}$ and $\rho_{\text {Silica }}=17.3610^{10} \mathrm{~cm}^{-2}$, calculated from the chemical composition, giving the electronic contrast $\Delta \rho=8.9510^{10} \mathrm{~cm}^{-2}$. Uncross-linked systems were measured in their glass cell, at SOLEIL (Saclay) on the beam-line SWING, with a single configuration defined by a wavelength of $\lambda=1.77 \AA(\mathrm{E}=7 \mathrm{keV})$ and a sample-to-detector distances of $6.5 \mathrm{~m}$. As the center of scattering was not coinciding with the one of the detector, this single configuration yield a remarkably large total Q-range from $110^{-3}$ to $1.610^{-1} \AA^{-}$

1, by merging two measurements with two different beam-stops (a small one and a large one). Standard data treatments include merging, subtraction and normalization. Cross-linked systems were measured at ESRF on the beam-line ID02, with a wavelength of $1 \AA(\mathrm{E}=12,4 \mathrm{keV})$ and two sample-to-detector distances of 1 and $10 \mathrm{~m}$, yielding a total Q range from $110^{-3}$ to $510^{-1} \AA^{-1}$. On the same beam-line, the Bonse-Hart setup allowed to reach the lower $Q$ value of $310^{-4} \AA^{-1}$. SAXS measurements were performed exclusively at rest, after accurate measurement of the thickness of samples. Standard treatments of data include isotropic averaging of the $2 \mathrm{D}$ isotropic scattering patterns, merging and normalization. After measuring the scattering of the unfilled system, the pure silica scattering in a nanocomposite of the silica volume fraction $\varphi_{\mathrm{SiO} 2}$, is obtained by subtracting for each sample the matrix contribution, according to the following operation: $\mathrm{I}_{\mathrm{SiO} 2}=\mathrm{I}_{\mathrm{Sample}}-\left(1-\varphi_{\mathrm{SiO} 2}\right) \times \mathrm{I}_{\mathrm{Matrix}}$.

\section{Transmission Electronic Microscopy TEM}

For TEM characterization, samples were cut by ultracryomicrotomy (mechanical cut) at $-80^{\circ} \mathrm{C}$ (lower than the glass transition temperature of SBR) at a desired thickness of about 50nm, then laid on a TEM grid before observation. Observations were realized using a Philips CM200 LaB6 (200kV) microscope in bright field mode. 


\section{Chain Conformation}

The scattering intensity of a single chain in a nanocomposite can be obtained directly by SANS using the zero average contrast (ZAC) method. This method was first used for a mix of normal, i.e., non deuterated (h) and deuterated (d) chain in a solvent: the total scattering intensity $\mathrm{I}(\mathrm{Q})$ can be expressed by the relation [41]:

$$
\mathrm{I}(\mathrm{Q})=\left(\rho_{\mathrm{d}}-\rho_{\mathrm{h}}\right)^{2} \phi_{\mathrm{h}} \phi_{\mathrm{d}} v \Phi \mathrm{NP}(\mathrm{Q})+\left(\phi_{\mathrm{d}} \rho_{\mathrm{d}+} \phi_{\mathrm{h}} \rho_{\mathrm{h}}-\rho_{0}\right)^{2}\left[v \Phi \mathrm{NP}(\mathrm{Q})+\mathrm{V} \Phi^{2} \mathrm{~S}(\mathrm{Q})\right]
$$

Where $\rho_{\mathrm{d}}, \rho_{\mathrm{h}}$ and $\rho_{0}$ are respectively the scattering length density of deuterated chains, hydrogenated chains and solvent, $\phi_{\mathrm{h}}, \phi_{\mathrm{d}}$ are the volume fractions of hydrogenated and of deuterated chains, $v$ is the volume of the monomer, $\Phi$ is the volume fraction of polymer, $\mathrm{V}$ is the global volume, $\mathrm{P}(\mathrm{Q})$ is the form factor of the chain, and $\mathrm{S}(\mathrm{Q})$ is the inter-chain structure factor. When the average contrast between polymer mixture and solvent is adjusted to zero, i.e.:

$$
\phi_{\mathrm{d}} \rho_{\mathrm{d}+} \phi_{\mathrm{h}} \rho_{\mathrm{h}}-\rho_{0}=0
$$

The scattering intensity is only related to the form factor of one chain:

$$
\mathrm{I}(\mathrm{Q})=\left(\rho_{\mathrm{d}}-\rho_{\mathrm{h}}\right)^{2} \phi_{\mathrm{h}} \phi_{\mathrm{d}} v \Phi \mathrm{NP}(\mathrm{Q})
$$

In our case, the role of the solvent is played by the silica particles. The scattering length density has been determined by previous contrast variations experiments [42] in solvent and found to be equal to $3.4110^{10} \mathrm{~cm}^{-2}$. For our system, the matching composition to satisfy equation (2) is achieved by mixing $54 \% \mathrm{v} / \mathrm{v}$ of hydrogenated SBR chains $\left(\mathrm{SLD}=0.5910^{10} \mathrm{~cm}^{-2}\right)$ and $46 \% \mathrm{v} / \mathrm{v}$ of deuterated SBR chains

$\left(\mathrm{SLD}=6.7410^{10} \mathrm{~cm}^{-2}\right)$. When both hydrogenated and deuterated chains have equivalent molecular weights and when there is no interaction between the monomer, for ideals mixture, the form factor of a single chain corresponds to a Gaussian chain in a melt whose scattering function can be described by the Debye function [43]: 


$$
\mathrm{P}(\mathrm{Q})=2 /\left(\mathrm{Q}^{2} \mathrm{R}_{\mathrm{g}}\right)^{2}\left[\mathrm{e}^{-\mathrm{Q}^{2} \mathrm{Rg}^{2}}-1+\mathrm{Q}^{2} \mathrm{R}_{\mathrm{g}}^{2}\right)
$$

Where $\mathrm{R}_{\mathrm{g}}$ is the radius of gyration of the chain. However mixtures of hydrogenated and deuterated chains are usually not ideal and one needs to introduce a monomeric interaction parameter (FloryHuggins) $\chi$. The equation (3) is extended to the random phase approximation (RPA) [44]:

$$
\frac{1}{\mathrm{I}(\mathrm{Q})}=\frac{1}{\Delta \rho^{2} \phi_{\mathrm{h}} \mathrm{N}_{\mathrm{h}} \mathrm{v}_{\mathrm{h}} \mathrm{P}_{\mathrm{h}}(\mathrm{Q})}+\frac{1}{\Delta \rho^{2} \phi_{\mathrm{d}} \mathrm{N}_{\mathrm{d}} \mathrm{U}_{\mathrm{d}} \mathrm{P}_{\mathrm{d}}(\mathrm{Q})}-\frac{2 \chi}{\Delta \rho^{2} \mathrm{~V}}
$$

Where $\phi_{\mathrm{d}, \mathrm{h}}, \mathrm{N}_{\mathrm{d}, \mathrm{h}}, v_{\mathrm{d}, \mathrm{h}}, \mathrm{P}_{\mathrm{d}, \mathrm{h}}(\mathrm{Q})$ are the volume fraction, the number of monomeric unit per chain, the volume of monomeric unit and the form factor of the chains respectively for the hydrogenated and for the deuterated SBR polymers. $\mathrm{V}$ is the average monomer volume $=\phi_{\mathrm{h}} v_{\mathrm{h}}+\phi_{\mathrm{d}} v_{\mathrm{d}}$. The molecular weight determination with SEC experiments permit to extract the $\mathrm{N}_{\mathrm{d}, \mathrm{h}} \mathrm{v}_{\mathrm{d}, \mathrm{h}}$ product like $\mathrm{M}_{\mathrm{wd}, \mathrm{h}}=\mathrm{dN}_{\mathrm{A}} \mathrm{N}_{\mathrm{d}, \mathrm{h}} \mathrm{v}_{\mathrm{d}, \mathrm{h}}$ where $\mathrm{d}$ is the density in $\mathrm{g} / \mathrm{cm}^{3}$ and $\mathrm{N}_{\mathrm{A}}$ the Avogadro number. As the two monomers have the same structure, the numbers of parameters can be simplified according to $R_{g d}=R_{g h}\left(M_{w d} / M_{w h}\right)^{1 / 2}$.

\subsection{Uncross-linked systems}
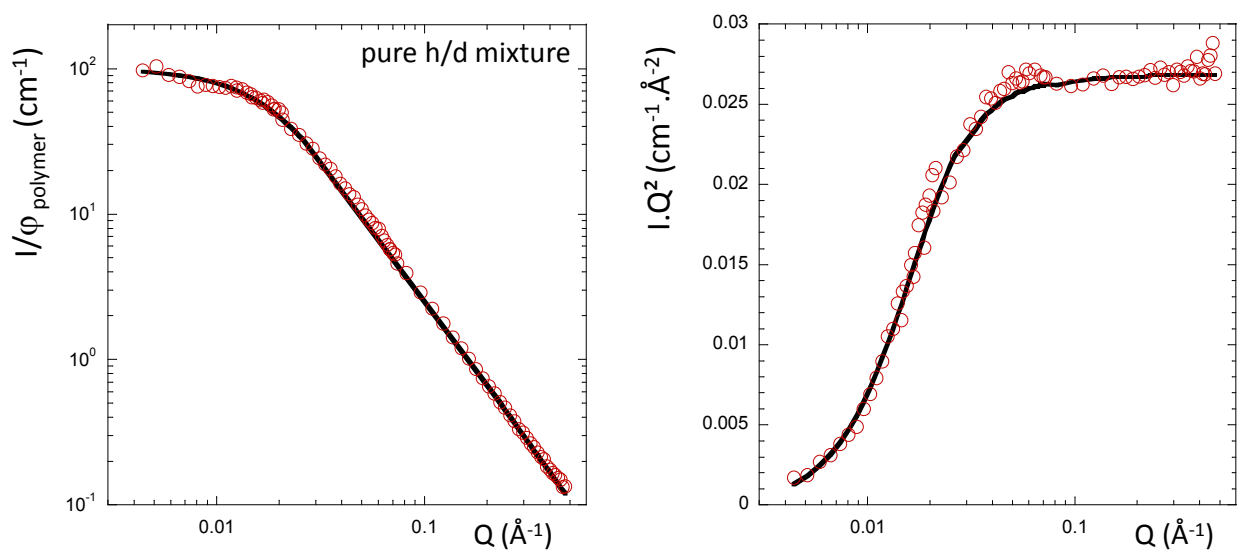

Figure 1: SANS curve the pure $\mathrm{h} / \mathrm{d}$ SBR chain mixtures at the ZAC composition in log-log representation (left) and I.Q2 versus Q Kratky representation (right). The full line is the best fitted obtained using the RPA function with the following parameters $\mathrm{R}_{\mathrm{gh}}=7.00 \mathrm{~nm}$ and $\chi=6.10^{-4}$. The error bar on the $\mathrm{R}_{\mathrm{g}}$ determination is $\pm 2 \%$. The curves have been scaled for clarity. 
The Figure 1 presents the normalized SANS curve obtained for the pure h/d SBR unierosse-linked mixture (batch 1) under the ZAC condition, without filler and additives. The curve is perfectly fitted with the RPA function that enables to extract the following parameters with an uncertainty equal to 5\%: $\mathrm{R}_{\mathrm{gh}}=7.00 \mathrm{~nm}$ and $\chi=610^{-4}$. The radius of gyration of the $\mathrm{d}$ chains can be deduced from the molecular masses ratio and is equal to $\mathrm{R}_{\mathrm{gd}}=8.30 \mathrm{~nm}$. We consider now the situation where we added increasing content of filler in the $\mathrm{h} / \mathrm{d}$ polymer matrix first without dispersing agents. The SANS curves are presented in Figure 2 for 1, 10 and 15\% vol. of silica. We can observe that up to a value of $0.01 \AA^{-1}$, all the curves superimpose perfectly with the pure $\mathrm{h} / \mathrm{d}$ matrix. Below this $\mathrm{Q}$ value, one can see an upturn of the low Q scattering that will be discussed in details below. We performed the SANS analysis with the RPA function (full black lines) by fixing the $\chi$ parameter to the $\mathrm{h} / \mathrm{d}$ blend value and fitted the $\mathrm{R}_{\mathrm{gh}}$ to the height of the Kratky plateau (only one fitting parameter). The resulting fitting $\mathrm{R}_{\mathrm{gh}}$ values are reported in the Table 1.
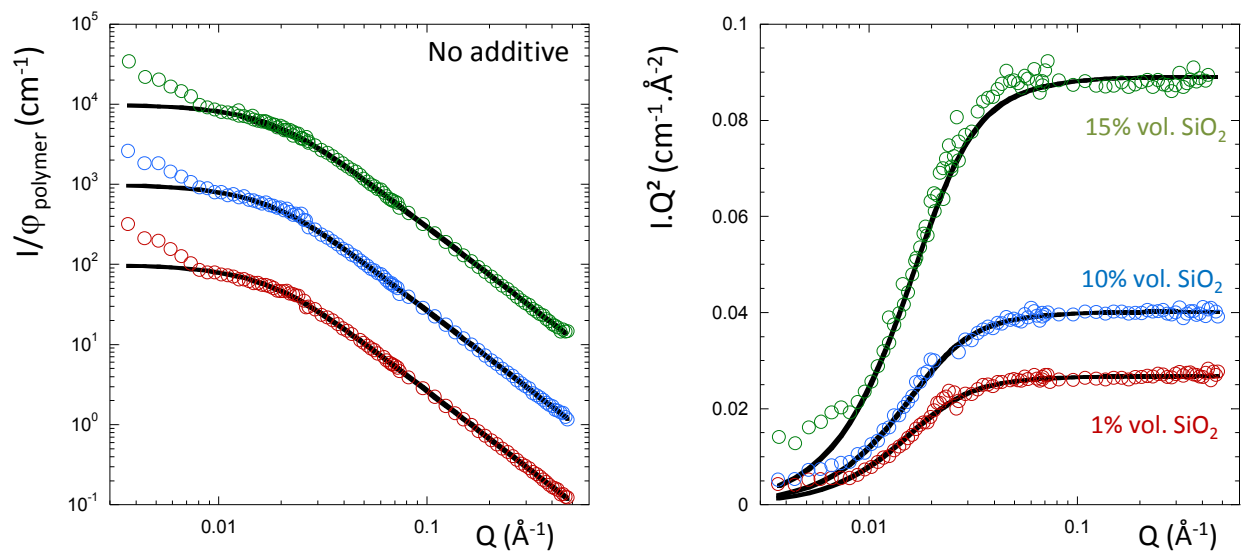

Figure 2: SANS curves for the silica filled h/d SBR chain mixtures at the ZAC composition without additives for $1 \%$ vol. (red dots), 10\% vol. (blue dots) and 15\% vol. of silica (green dots) in log-log (left) and Kratky (right) representation. The full black lines are the best fitted obtained with the RPA function (see text). The curves have been scaled for clarity. 
We now consider the influence of the dispersing additive using the coating agent OCTEOrthattinean covalently bind to the surface of the silica and is known to improve the compatibility with the polymer. The different series containing respectively 1 and 4 equivalent ( 1 and 4 TEOS group per nm² of silica) of coating agent have been probed with SANS for 1, 10 and 15\% vol. of silica filler (Figure 3 ). We previously double-checked that the additives do not contribute to the SANS scattering by comparing the pure $\mathrm{h} / \mathrm{d}$ blend with the same blend with the same amount of OCTEO or Si69. No specific scattering coming from the additive can be detected with SANS.
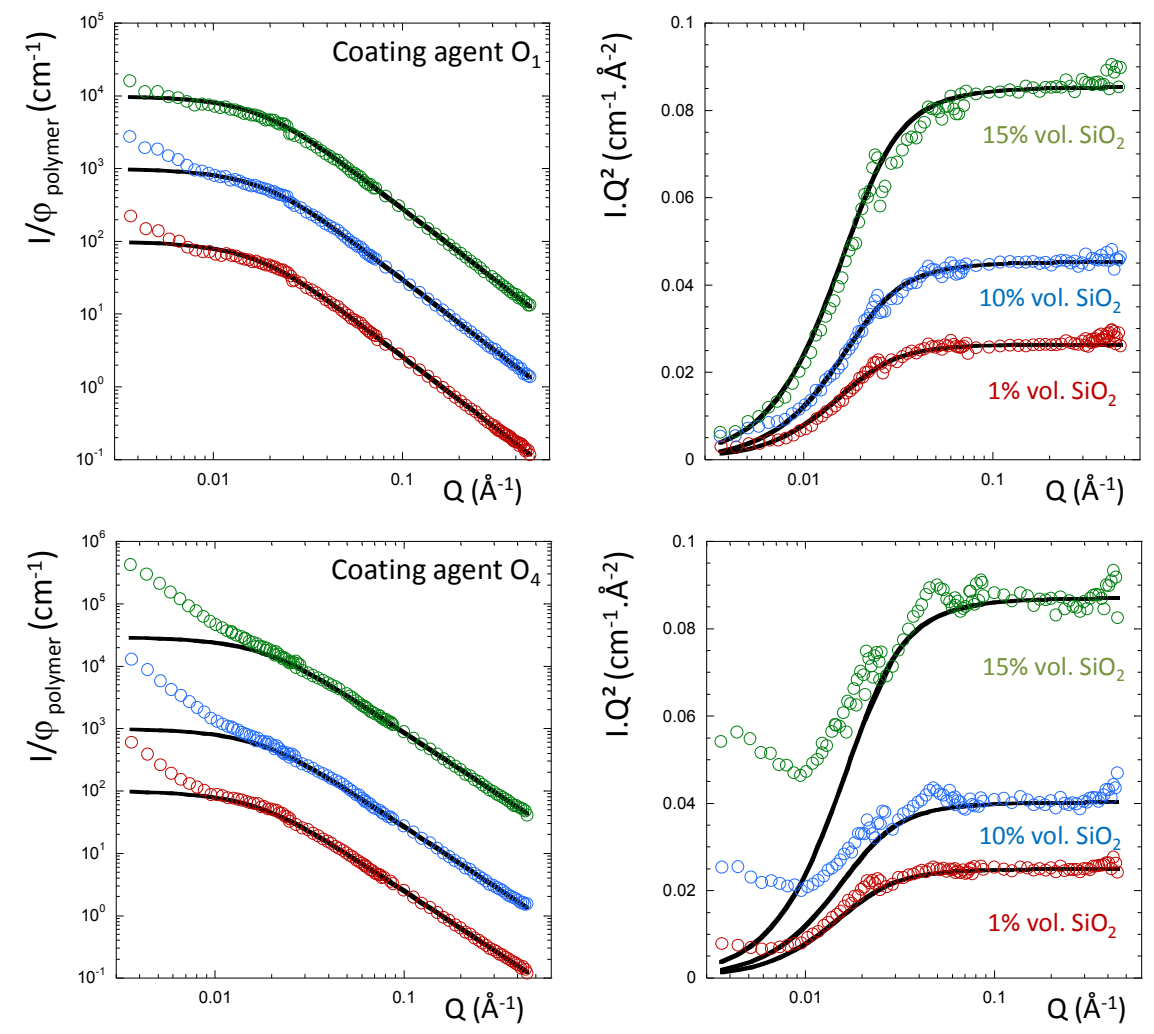

Figure 3: SANS curves for the silica filled h/d SBR chain mixtures at the ZAC composition with (top) on equivalent of coating agent $\left(\mathrm{O}_{1}\right)$ for $1 \%$ vol. (red dots), 10\% vol. (blue dots) and 15\% vol. of silica (green dots), and (bottom) with 4 equivalent of coating agent $\left(\mathrm{O}_{4}\right)$ for $1 \%$ vol. (red dots), 10\% vol. (blue dots) and 15\% vol. of silica (green dots) in log-log (left) and Kratky (right) representations. The black full lines are the best fitted obtained with the RPA function. The curves have been scaled for clarity. 


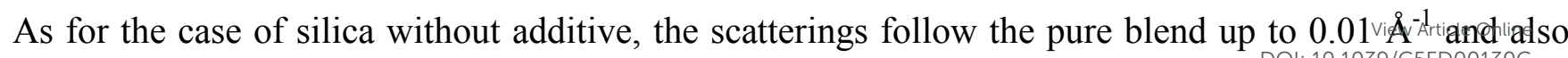
reveal an upturn for the low Q region. This effect is especially pronounced when increasing the content of coating agent $(\mathrm{O} 4)$ for high filler content 10 and 15\% vol. of silica. This is illustrated by a decrease of the agreement between the experimental data and the RPA calculation, which is particularly visible in the Kratky representation.
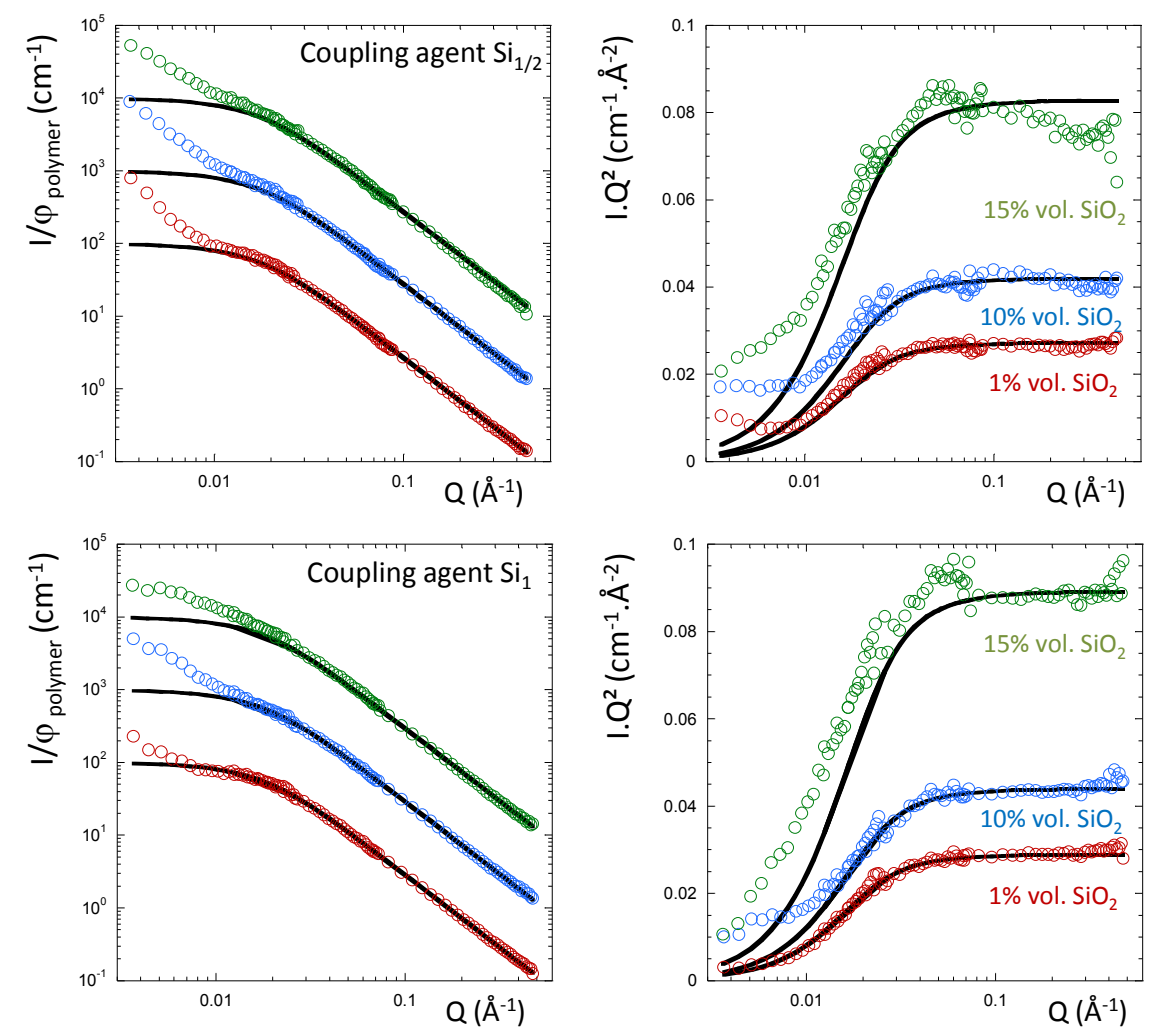

Figure 4: SANS curves for the silica filled h/d SBR chain mixtures at the ZAC composition with (top) $1 / 2$ equivalent of coupling agent $\left(\mathrm{Si}_{1 / 2}\right)$ for $1 \%$ vol. (red dots), 10\% vol. (blue dots) and $15 \%$ vol. of silica (green dots), and with (bottom) 1 equivalent of coupling agent ( $\left.\mathrm{Si}_{1}\right)$ for $1 \%$ vol. (red dots), $10 \%$ vol. (blue dots) and 15\% vol. of silica (green dots) in log-log (left) and Kratky (right) representations. The full line is the best fitted obtained with the RPA function. The curves have been shifted for clarity.

A similar trend is observed with $1 / 2$ and 1 equivalent of the coupling agent Si69 that can be covalently bonded to the particles and the polymer chains. Up to $0.01 \AA^{-1}$, the scattering again follows the blend 
signal but an upturn appears at low Q that disturbs the agreement between the experimentalidatailapidnthe RPA calculation. We performed the RPA analysis by fixing the Flory parameter to $610^{-4}$ and fitted the $\mathrm{R}_{\mathrm{g}}$ of the $\mathrm{h}$ chains. Results are reported on the table 1 for the different experimental conditions.

\begin{tabular}{|c|c|c|c|c|}
\hline & $\begin{array}{c}\text { Pure h/d blend } \\
\mathrm{R}_{\text {gh }}(\mathrm{nm})\end{array}$ & $\begin{array}{c}1 \% \text { vol. } \mathrm{SiO}_{2} \\
\mathrm{R}_{\text {gh }}(\mathrm{nm})\end{array}$ & $\begin{array}{c}10 \% \text { vol. } \mathrm{SiO}_{2} \\
\mathrm{R}_{\text {gh }}(\mathrm{nm})\end{array}$ & $\begin{array}{c}15 \% \text { vol. } \mathrm{SiO}_{2} \\
\text { No additive }\end{array}$ \\
\hline Coating agent $\mathrm{O}_{1}$ & 7.00 & 7.00 & 7.00 & 6.65 \\
\hline Coating agent $\mathrm{O}_{4}$ & 7.00 & 7.05 & 6.60 & 6.80 \\
\hline Coupling agent $\mathrm{Si}_{1 / 2}$ & 7.00 & 7.25 & 7.00 & 6.90 \\
\hline Coupling agent $\mathrm{Si}_{1}$ & 7.00 & 6.95 & 6.85 & 6.65 \\
\hline
\end{tabular}

Table 1: $\mathrm{R}_{\mathrm{gh}}$ values deduced from the RPA analysis by fixing the $\chi$ to the initial blend value $6.10^{-4}$. The uncertainty is $\pm 5 \%$.

\subsection{Cross-linked systems}

The Figure 5 presents the SANS curves obtained with the cross-linked samples (batch 2). We can notice that crosslinking modified the $\mathrm{h} / \mathrm{d}$ blend with the appearance of a peak visible in the Kratky representation. This peak is related to an intra-chain correlation induced by the crosslinking process. The mean distance between two junctions in the Gaussian pathway is reduced with a resulting modification of the chain form factor. Such a form factor has already been computed by Bastide et al. [45]. We choose not to use this formula for the present study that is beyond the scope of the paper. In addition, RPA is still valuable in the Guinier regime to capture the $R_{g}$ values and it variations as function of filler content, additive and elongation rates. We get the following parameters with a larger 


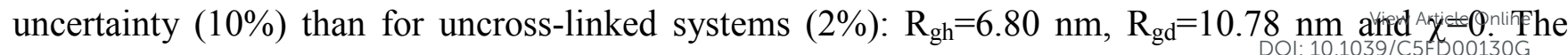
value for the $\mathrm{h}$ chains is a little bit smaller than the one obtained for uncross-linked chains as expected from the intra-chains correlation effects. For the same reason, we can see a drop of the Flory parameter. One gets a higher value for the $\mathrm{d}$ chains due to the larger dispersion of the molecular masses for the batch 2 . We applied the same analysis in presence of coating and coupling agent for $1 \%$ vol. and $5 \%$ vol. of silica. The best fitted values of the $\mathrm{R}_{\mathrm{gh}}$ are reported in Table 2 .
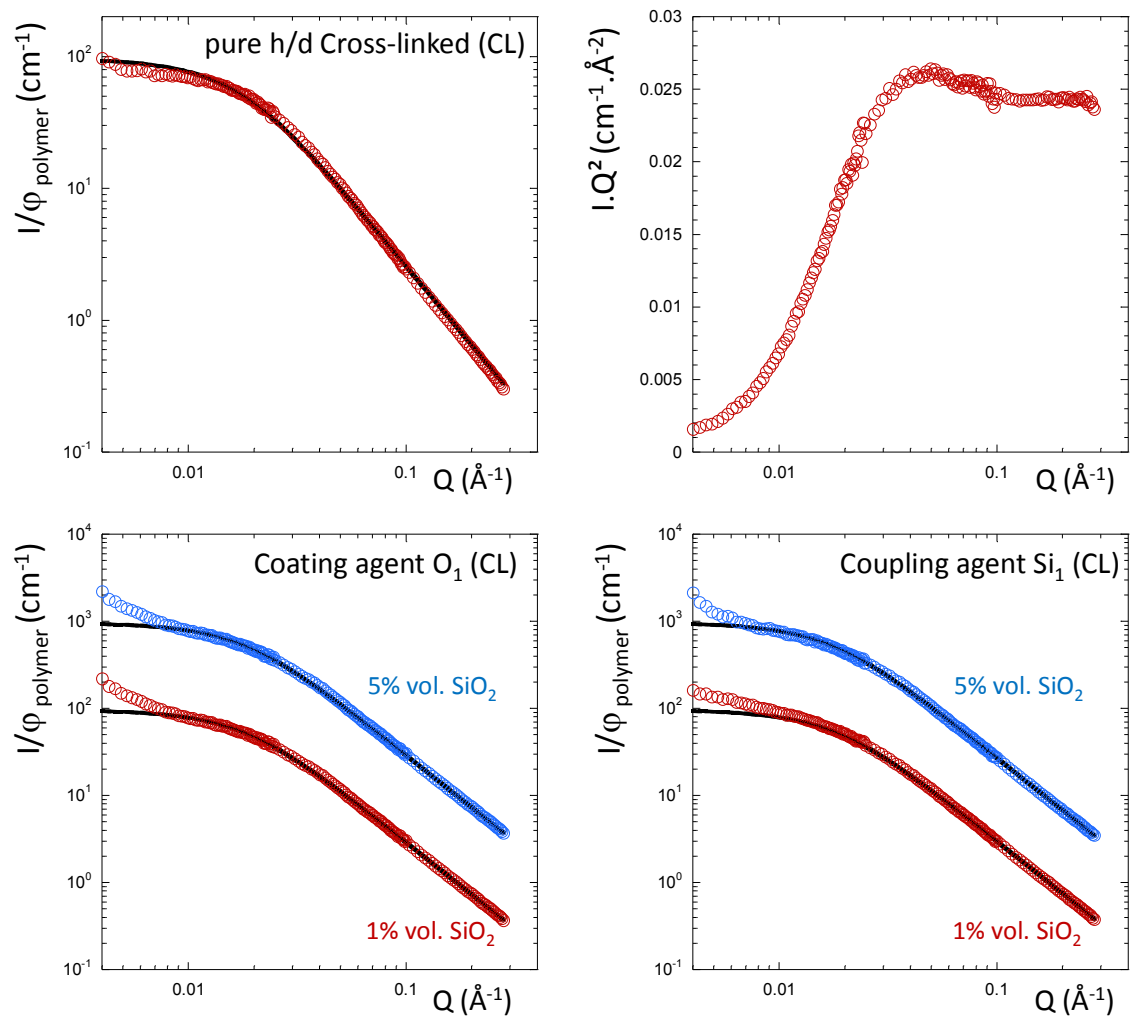

Figure 5: (top) SANS curves for the pure h/d SBR chain cross-linked (CL) mixtures at the ZAC composition in log-log (left) and Kratky (right) representation. (bottom) SANS curves for silica filled $\mathrm{h} / \mathrm{d}$ SBR chains cross-linked (CL) composites with (left) 1 equivalent of coating agent $\left(\mathrm{O}_{1}\right)$ for $1 \%$ vol. (red dots) and $5 \%$ vol. (blue dots), and (right) 1 equivalent of coupling agent ( $\left.\mathrm{Si}_{1}\right)$ for $1 \%$ vol. (red dots) and 5\% vol. (blue dotes) of silica. The full line is the best fitted obtained with the RPA function. The curves have been shifted for clarity. 


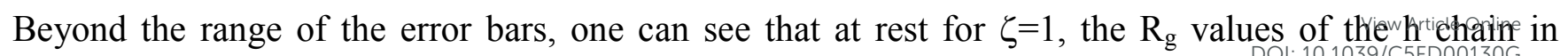
presence of filler and additives do not seem to be different to the uncross-linked situation. That suggests that cross-linking does not modify significantly the polymer chain conformation in nanocomposites. We stretched the samples for different elongation rates $\zeta=1.3,1.5$ and 1.8 and compared the pure chain deformation with the one in presence of silica (1\% and 5\% Vol.) and 1 equivalent of coating and coupling agents. We show only two cases, the pure $\mathrm{h} / \mathrm{d}$ and the coating $\mathrm{O}_{1}$ at $5 \%$ vol. of silica. The results are reported in Figure 6 for two specific averaging directions, parallel (left) and perpendicular (right) to the stretching direction in log-log and Kratky representations.

\begin{tabular}{|c|c|c|c|c|}
\hline & $\zeta=1$ & $\zeta=1.3$ & $\zeta=1.5$ & $\zeta=1.8$ \\
Sample & $\mathrm{R}_{\mathrm{gh} \text { isotropic }}$ & $\mathrm{R}_{\mathrm{gh}} / /-\mathrm{R}_{\mathrm{gh} \perp}$ & $\mathrm{R}_{\mathrm{gh}} / /-\mathrm{R}_{\mathrm{gh} \perp}$ & $\mathrm{R}_{\mathrm{gh}} / /-\mathrm{R}_{\mathrm{gh} \perp}$ \\
& $(\mathrm{nm})$ & $(\mathrm{nm})$ & $(\mathrm{nm})$ & $8.20-5.60$ \\
\hline Pure h/d blend & 7.00 & $7.10-5.90$ & $7.50-5.80$ & $10.00-5.60$ \\
\hline Coating $\mathrm{O}_{1} 1 \%$ vol. $\mathrm{SiO}_{2}$ & 6.95 & $7.80-6.10$ & $8.60-5.80$ & $9.50-5.20$ \\
\hline Coating $\mathrm{O}_{1} 5 \%$ vol. $\mathrm{SiO}_{2}$ & 6.70 & $7.50-5.70$ & $8.10-5.40$ & - \\
\hline Coupling $\mathrm{Si}_{1} 1 \%$ vol. $\mathrm{SiO}_{2}$ & 6.60 & $7.10-5.70$ & $7.90-5.70$ & $9.50-5.70$ \\
\hline Coupling $\mathrm{Si}_{1} 5 \%$ vol. $\mathrm{SiO}_{2}$ & 7.10 & $7.70-6.10$ & $8.80-6.00$ & \\
\hline
\end{tabular}

Table 2: $R_{\mathrm{gh}}$ values deduced from the RPA analysis by fixing the $\chi$ to the initial blend value equal to 0 . The uncertainty is $\pm(\mathrm{nm}) 10 \%$. 

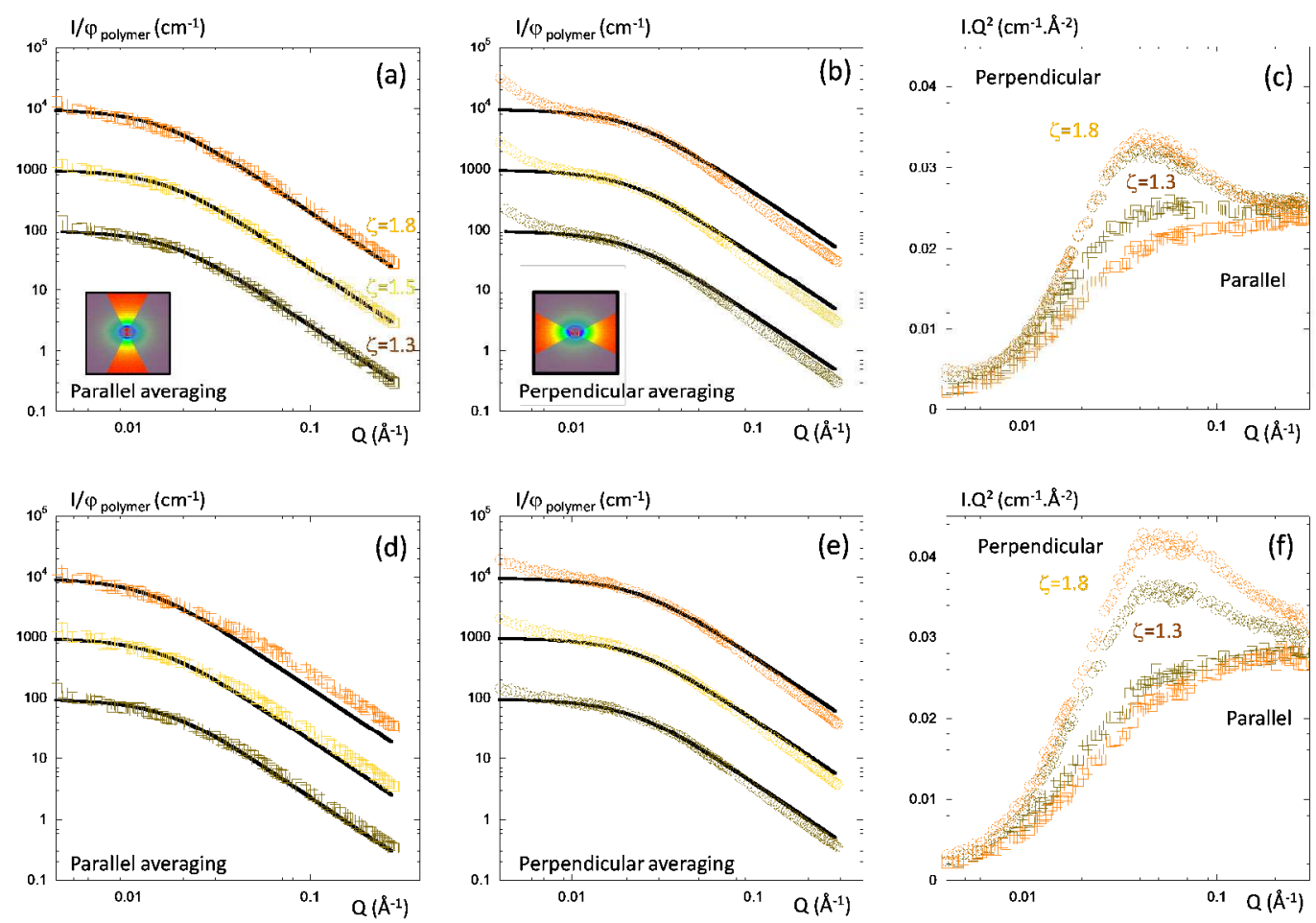

Figure 6: SANS for cross-linked stretched samples at different elongation ratio $\zeta=1.3$ (brown), 1.5 (yellow) and 1.8 (orange), (a) pure matrix averaged in parallel direction, (b) pure matrix averaged in perpendicular direction, (c) pure matrix average in parallel and perpendicular direction in kratky representation, (d) Composite filled with coating agent $\mathrm{O}_{1}$ at $5 \%$ vol. of silica averaged in parallel direction, (e) Composite filled with coating agent $\mathrm{O}_{1}$ at 5\% vol. of silica averaged in perpendicular direction, (f) Composite filled with coating agent $\mathrm{O}_{1}$ at $5 \%$ vol. of silica average in parallel and perpendicular direction in kratky representation. The inset pictures illustrate the parallel and perpendicular averaging of the scattering intensity. The full black lines are RPA calculation. The curves in log-log representation have been scaled for clarity.

We applied the RPA analysis on elongated samples the same way as the non-elongated ones. The variations of the $R_{g h}$ as a function of the elongation rate are reported in Table 2. Under elongation, the deformation is lost at large angle (loss of affinity), the chains adopted their initial configuration for 
small distances, typically for distances smaller than the mean distance between two crossistinking junctions.

\section{Nanoparticles Assembly}

We performed SAXS experiments to evaluate the NP dispersion inside the polymer blend. For X-rays radiation the contrast is mainly between silica particles and the polymer matrix (there is no contribution of the labelling $\mathrm{h} / \mathrm{d}$ chains). The experiments have been made on the same samples prepared for SANS. The SAXS curves are presented in Figure 7 for the different conditions (no additive, coating and coupling agent) as function of the silica loading. For comparison, we reported the spherical form factor of the primary particles (full black line) previously determined [18].
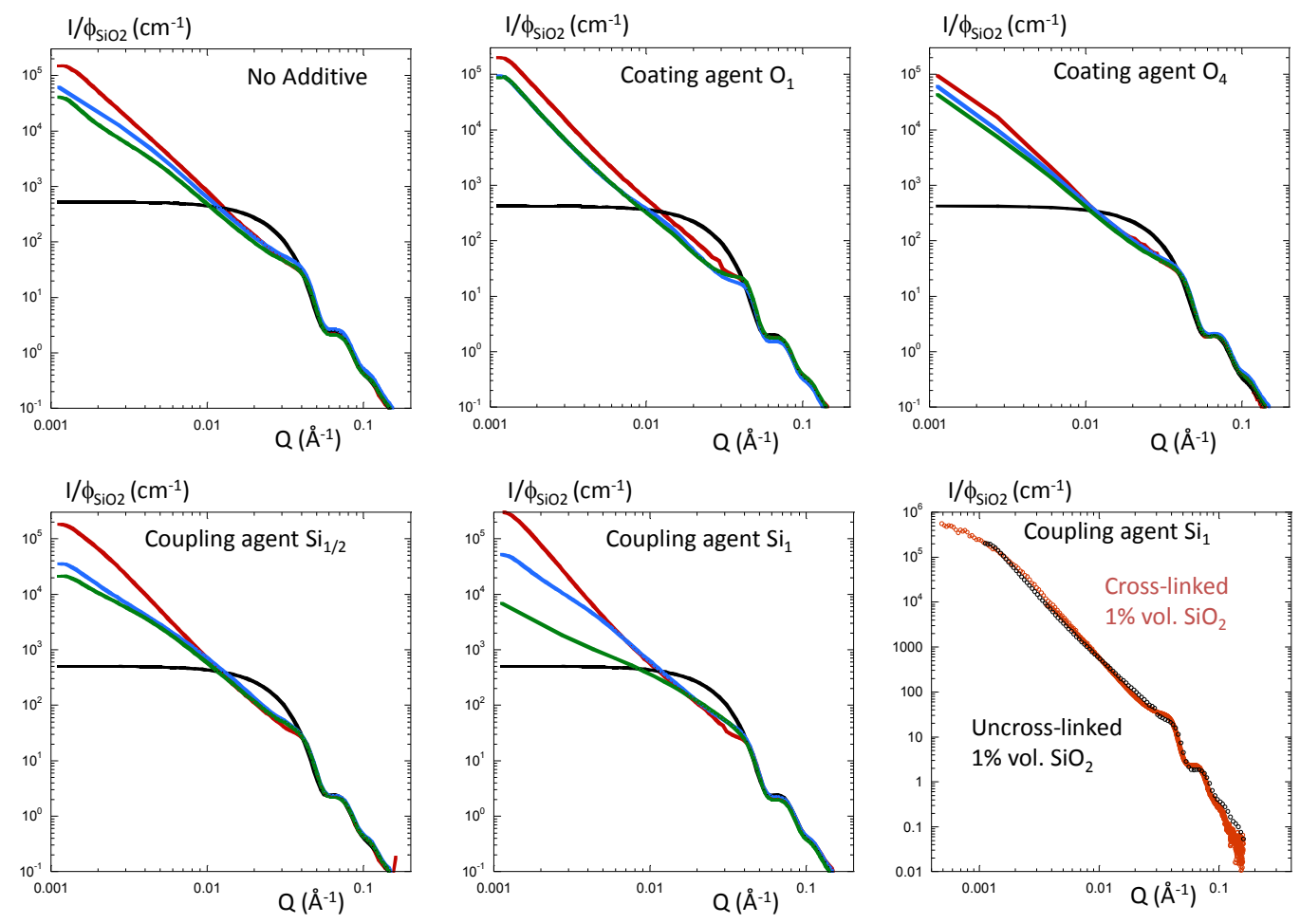

Figure 7: SAXS curves for the different conditions (top) no additive and coating agent $\left(\mathrm{O}_{1}\right.$ and $\left.\mathrm{O}_{4}\right)$ (bottom) coupling agent $\left(\mathrm{Si}_{1 / 2}\right.$ and $\left.\mathrm{Si}_{1}\right)$ as function of the silica volume fraction $1 \%$ vol. (red line), 10\% vol. (blue line) and 15\% vol. (green line). The black line is the form factor of the primary particles 
calculated using a spherical function convoluted with a log-normal distribution with Rom $7: 8 \mathrm{~nm}$ mirand $\sigma=0.15$. The bottom/right plot illustrates the effect of cross-linking on the NP dispersion. The curves have been normalized by the silica volume fraction.

We can observe a systematic increase of the low Q scattering suggesting that the primary particles are aggregated inside the polymer matrix and are forming clusters of NPs. The slope of the decrease of the intensity in the intermediate $\mathrm{Q}$ range, close to 3, indicates the formation of compact aggregates. We can also observe a diminution of the low Q scattering level when increasing the particle volume fraction coming from an increase of the interaction between the clusters arising when the clusters are forming a continuous connected network as a result of a percolation process. The absence of plateau prevents the determination of a characteristic size of the clusters. The formation of cluster seems to be systematic and not controlled by the nature and the quantity of the additives. That can be due to the low molecular weight of the matrix used (40k) that gives rise to a very low viscosity that cannot balanced the cluster formation during the solvent casting process. To evaluate the influence of the crosslinking on the NP assembly, we compared the SAXS curves for all the samples uncross-linked and cross-linked. One example is given in Figure 7 (bottom/right). We can see that the scattering superimposed perfectly illustrating that cross-linking do not modify the NP assembly inside the polymer matrix. We completed the analysis with TEM pictures presented in Figure 8. TEM pictures confirmed the formation of dense and compact aggregates that are interacting at shorter distance when increasing the silica volume fraction. We can see clearly the transition from individual clusters to the formation of a continuous network visible for $10 \%$ vol. of silica. To evaluate the size of the clusters, we calculated the radially averaged autocorrelation function $\mathrm{C}(\mathrm{r})$ using the image processing software ImageJ [46]. C(r) basically calculates the two-point correlation of the pixels of an image, after applying a binary filter, as a function of distance and gives information about the typical feature size in an image. The crossing line with zero gives the cluster sizes as illustrated in Figure 8 which are respectively $170 \mathrm{~nm}$ and $115 \mathrm{~nm}$ for 1 and $10 \%$ vol. of silica which is consistent with the filler network formation. 

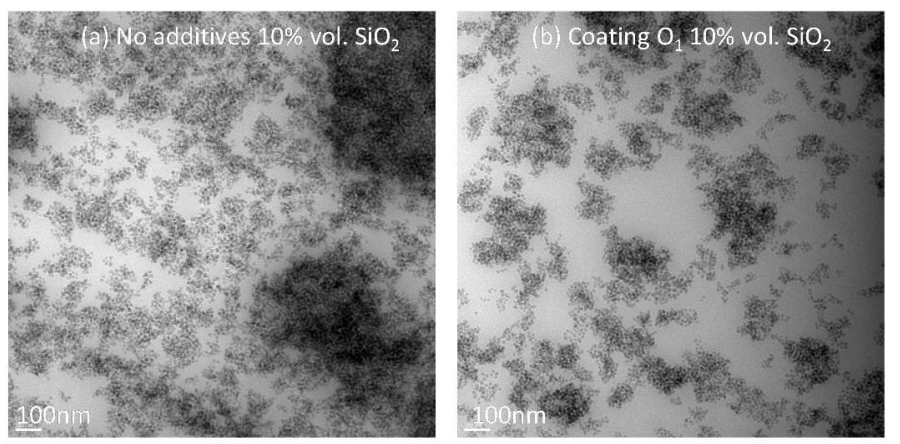

View Article Online DOI: 10.1039/C5FD00130G
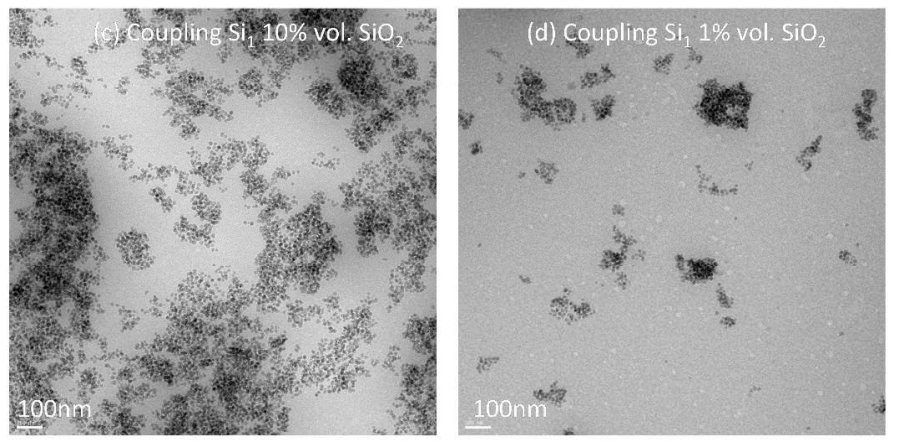

Figure 8: TEM pictures for $\mathrm{h} / \mathrm{d}$ blends filled with (a) no additive at $10 \%$ vol. of silica, (b) coating agent at $10 \%$ vol. of silica, (c) coupling agent at $1 \%$ vol. of silica and (d) coating agent at $10 \%$ vol. of silica.

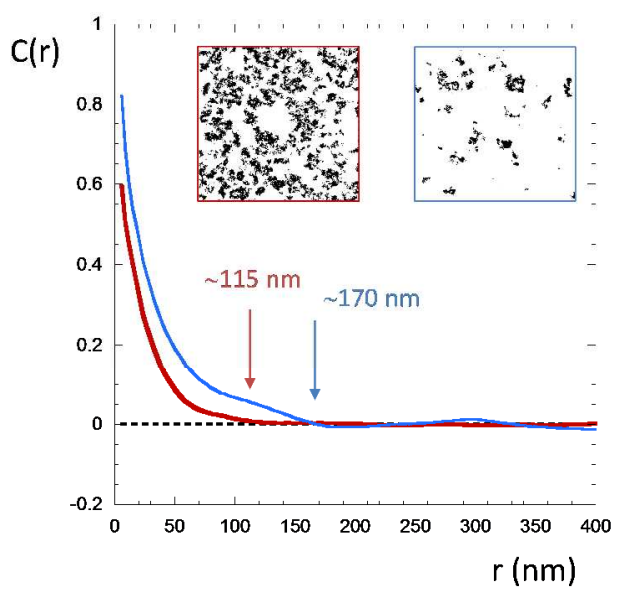

Figure 9: $\mathrm{c}(\mathrm{r})$ on TEM pictures for (red) coating agent $\mathrm{O}_{1}$ at $10 \%$ vol. of silica and (blue) coupling agent $\mathrm{Si}_{1}$ at $1 \%$ vol. of silica. 
As previously shown through the different results, we can have access to the radius of gyration of the SBR chains for uncross-linked and cross-linked filled nanocomposites at rest and under uniaxial elongation. We can manage the NP assembly from individual clusters to a continuous filler network with the NP loading, coating and coupling additives. We successfully used the RPA function to analyze the SANS data with most of the time a consistent agreement between the model and the experimental points for both uncrosslinked and crosslinked systems. However, one can observe for some situations a discrepancy especially in Figures 3 and 4. The most probable explanation of this discrepancy is an unperfect matching of the silica.
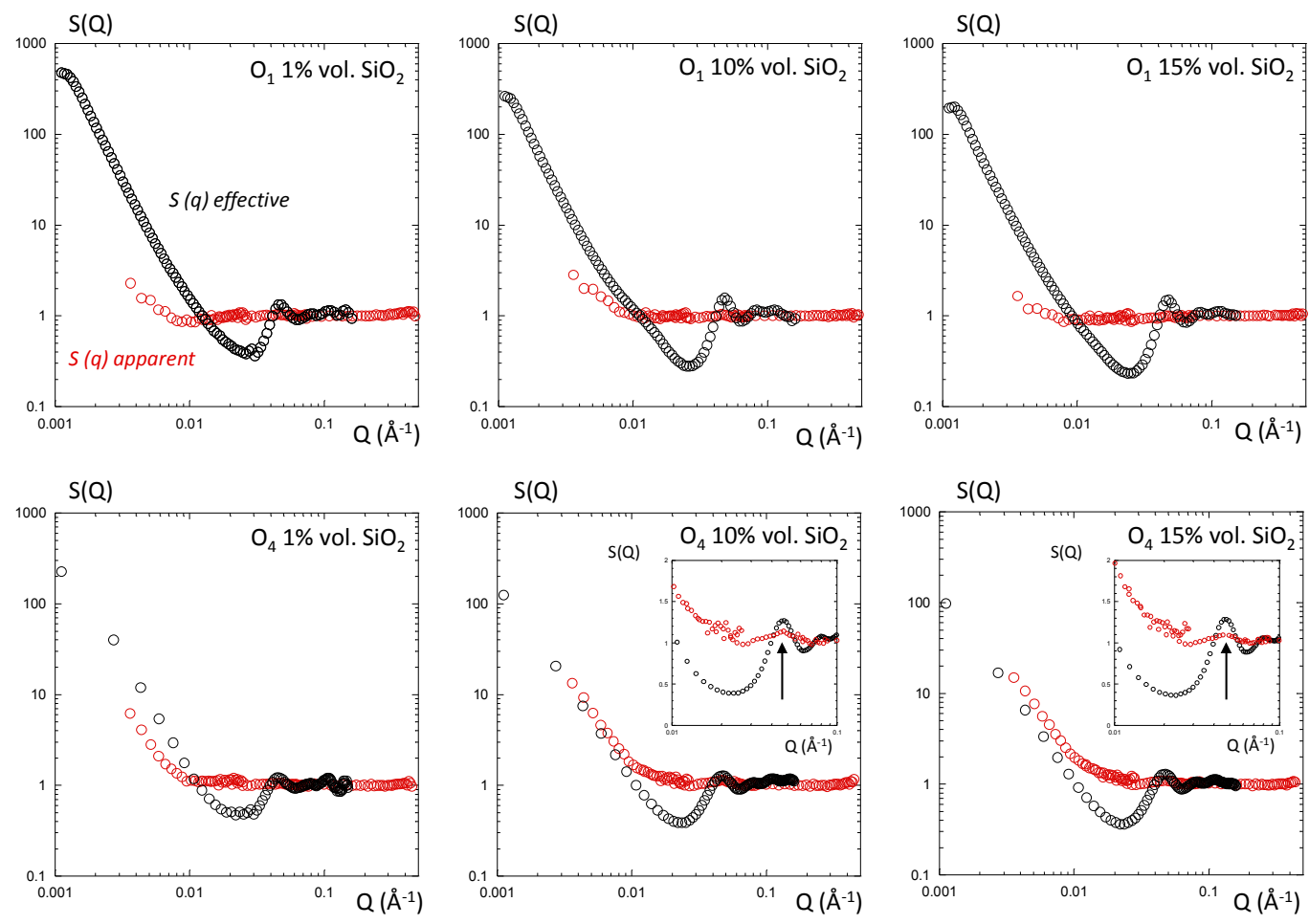

Figure 10: Comparison between effective structure factor $S(Q)$ deduced from SAXS and apparent structure factor deduced from SANS for (top) coating agent O1 series and (bottom) coating agent O4 series. The inset is a zoom to highlight the NP-NP peak interactions. 
This can be illustrated with the following idea: for un-perfect matching, the SANS cturveicwithebe modified by a contribution of the NP structure factor. We thus divide the SANS scattering intensity by the chain form factor, calculated with the RPA function, to extract an "apparent" structure factor. We compared this apparent structure factor deduced from SANS with the "effective" NP structure factor that can be calculated by dividing the SAXS intensity by the well-known NP form factor. The structure factors have been determined from intensities in absolute unit and normalized by the x-rays and neutron contrast terms. We report two examples of such comparison in Figure 10 for the two series containing 1 (top) and 4 equivalent (bottom) of coating agent. For complete silica matching, the SANS signal remain below the SAXS as can be seen for the $\mathrm{O}_{1}$ series. However, for uncompleted silica matching, the SANS becomes equal or even larger than the SAXS scattering. In addition, we can see the appearance of a peak (in the inset) that corresponds exactly to the NP-NP interactions, NP in close contact inside the cluster that is visible on both apparent and effective structure factors. There is always a low Q contribution on the SANS scattering, beyond the size of the polymer chain, which is enhanced for unperfect matching of the filler. The typical size of this contribution can be evaluated approximatively using a simple Guinier function that gives $\mathrm{R}_{\mathrm{g}}=50 \mathrm{~nm}$ and $40 \mathrm{~nm}$ for $1 \%$ vol. and $10 \%$ vol. of silica. One can evaluate the corresponding sphere equivalent size using the relation $R_{g}{ }^{2}=3 / 5 R^{2}$ and we obtain typical diameter of $130 \mathrm{~nm}$ and $105 \mathrm{~nm}$ for respectively $1 \%$ and $10 \%$ vol. of silica. These values are similar whatever the additives used. The interesting feature here is that these values are close to the silica cluster size determined from the TEM analysis in Figure 9. That means that we can see the large cluster with SANS even if the contrast matching condition is reached. This effect can be due to specific random adsorption of $\mathrm{h}$ or $\mathrm{d}$ chains at the surface of the particles during the sample processing. A recent study has estimated an average grafting density of 0.01 chains $/ \mathrm{nm}^{2}$ corresponding to adsorbed bound layer in similar NP-polymer systems [47]. This amount, around a 1-2 nm adsorbed monolayer, is sufficient to modify the mean scattering neutron contrast of the cluster that makes them visible even under the ZAC condition. An alternative explanation should be that NP induced the formation of $\mathrm{h} / \mathrm{d}$ phase separation domains of typical sizes close to the silica cluster size $\left(\mathrm{R}_{\mathrm{g}} \sim 30-50 \mathrm{~nm}\right)$. A rapid simulation shows us 
that even a very low amount of the domains, typically $0.01 \%$ in volume fraction, is enoughvitoreatenthe DOI: 10.1039/C5FD00130C

low Q additional scattering. However, due to the limited number of data in the low Q regime (5-6 points), this is difficult to going further in the quantitative analysis and to conclude clearly between the different explanations. One way to check this idea deeply should be to anneal the sample for a longer time at high temperature to see whether the low Q contribution is decreasing due to chains desorption or not.
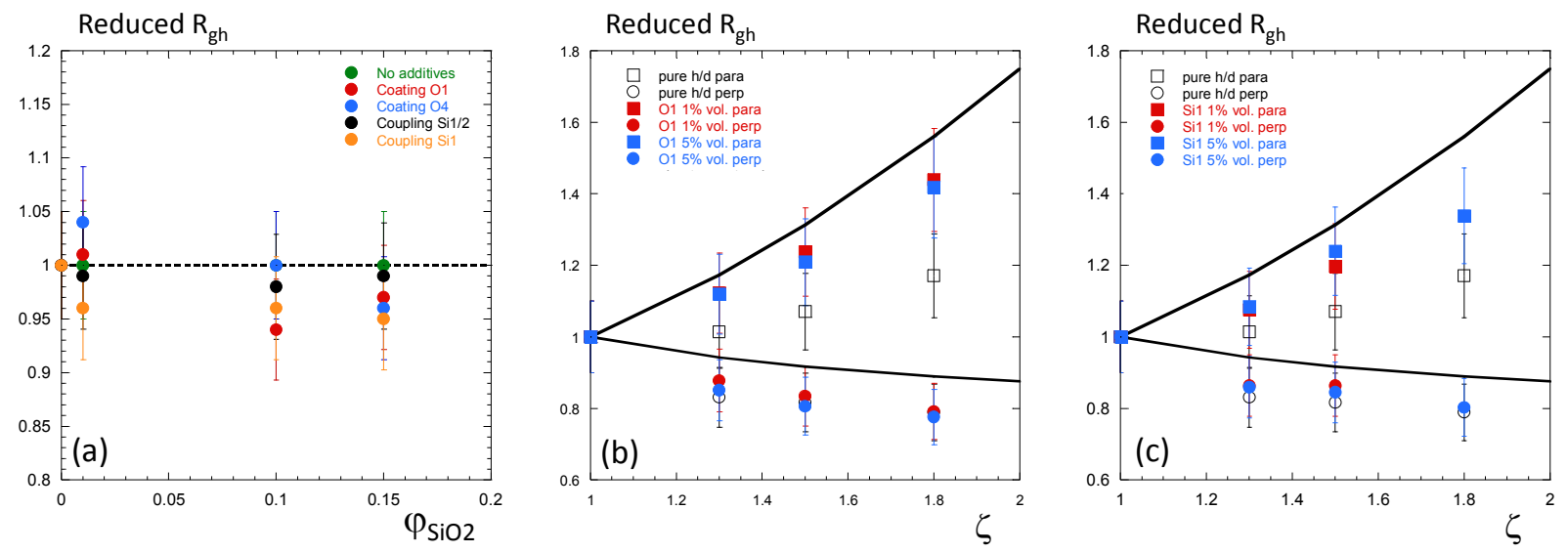

Figure 11: Reduced radius of gyration of $h$ chains (a) uncross-linked samples as function of the silica volume fraction, (b) for cross-linked stretched samples containing 1 equivalent of coating agent for 0,1 and $5 \%$ vol. of silica as function of the elongation rate and (c) for cross-linked stretched samples containing 1 equivalent of coupling agent for 0,1 and $5 \%$ vol. of silica as function of the elongation rate. The full black line is the phantom network deformation model.

The question of the low Q contribution and its influence on the determination of the polymer chain conformation is always a critical point when considering the chain conformation in presence of filler. Here we demonstrated that whatever the matching condition (perfect or not), the low Q contribution, certainly related to the silica cluster, can be treated separately from the determination of the radius of gyration of the polymer chains. As a result, we can follow the evolution of the normalized radius of 
gyration of the uncross-linked $h$ chains from the values reported in Table 1. The normalized $R$ ghlinthe ratio between the filled and unfilled values, are reported in Figure 11a. This representation show clearly that the polymer chain conformation at rest is not modified within a range of $\pm 5 \%$ whatever the degree of confinement by the filler (managed by the NP loading) and whatever the degree of interaction between the NP and the matrix (the nature and amount of additives). This is the first conclusion of the present study which is line with several previous conclusions on model systems [27, 28, 29, 31, 32, 33]. The cross-linking of the samples does not modify the NP assembly and the chain conformation. Then one can directly compare the pure chain deformation with the one in presence of filler, coating (Figure 11b) and coupling agent (Figure 11c). We also computed the theoretical phantom network model deformation [48] for a functionality $\mathrm{f}=4$ for comparison. On can see that the pure polymer is less deformed compared to the theoretical prediction especially in parallel direction. This can be due to the chain relaxation during the deformation that can occur for low cross-linking, namely only 3 crosslinking junction par chains. Surprisingly this effect is reduced in presence of filler for which the chain deformation is closer to the theoretical prediction in parallel direction. Silica cluster can then act as additional cross-linking junctions reducing the chain relaxation and then enhancing the chain deformation. Such conclusions are of a great interest for further understanding of the macroscopic mechanical properties of these materials. 


\section{Summary and Conclusion}

We report a complete study about the interplay between polymer chain conformations with NP assembly in model industrial SBR/silica nanocomposites. By mixing $\mathrm{d}$ and $\mathrm{h}$ chains, we applied the ZAC method with SANS that enables to extract the polymer chain form factor while matching the silica filler contribution. SAXS/TEM permits to characterize the NP assembly as function of NP loading and dispersing agent, coating and coupling additives. NPs are forming individual clusters at low loading that can connect to form a continuous network at high silica loading. Using RPA analysis, we show that the radius of gyration of the polymer chain remains unchanged - compared to the pure polymer - within a range of $\pm 5 \%$ whatever the crosslinking, the degree of confinement induced by NP loading and the degree of interaction between NP and polymer balanced by the nature (coating or coupling) and the amount of the dispersing additives. The extra scattering at low $Q$, that do not influenced the $R_{g}$ determination, can be attributed to NP cluster whose neutron contrast is enhanced from ZAC condition by trapped $\mathrm{h} / \mathrm{d}$ chains due to randomly chain adsorption at the surface of the NPs. Under stretching, NP acts as additional cross-linked junction preventing the chains relaxations that are deformed of a larger amplitude than the pure polymer.

\section{Acknowledgments}

We thank G. Baeza, A.-C. Genix and J. Oberdisse (LCC, Montpellier) for fruitful discussions. We acknowledge S. K. Kumar (Columbia University) for critical review of this work. 


\section{REFERENCES}

[1] Jancar, J.; Douglas, J. F.; Starr, F. W.; Kumar, S. K. ; Cassagnau, P. ; Lesser, A. J. ; Sternstein, S.

S. ; Buehler, M. J. Polymer, 2010, 51(15), 3321-3343.

[2] Tjong, S. C. Materials Science and Engineering, 2006, R 53, 73-197.

[3] Akcora, P.; Liu, H.; Kumar, S. K.; Moll, J.; Li, Y.; Benicewicz, B. C.; Schadler, L. S.; Acehan, D.; Panagiotopoulos, A. Z.; Pryamitsyn, V.; Ganesan, V.; Ilavsky, J.; Thiyagarajan, P.; Colby, R. H.; Douglas, J. Nat. Mater. 2009, 8, 354-359.

[4] Chevigny, C.; Jouault, N.; Dalmas, F.; Boué, F.; Jestin, J. Journal of Polymer Science Part B: Polymer Physics, 2011, 49(11), 781-791.

[6] Sunday, D.; Ilavsky, J.; Green, D. L. Macromolecules 2012, 45, 4007-4011.

[7] Jouault, N.; Vallat, P.; Dalmas, F.; Said, S.; Jestin, J.; Boué, F. Macromolecules, 2009, 42(6), 20312040.

[8] Tatou, M. ; Genix, A.-C. ; Imaz, A. ; Forcada, J. ; Banc, A. ; Schweins, R. ; Grillo, I. ; Oberdisse, J. Macromolecules, 2011, 44(22), 9029-9039.

[11] Robbes, A.-S ; Cousin, F. ; Meneau, F. ; Dalmas, F. ; Boué, F. ; Jestin, J. Macromolecules, 2011, $44(22), 8858-8865$.

[12] Klüppel, M.; Heinrich, G. Rubber Chem. Technol. 1995, 68, 623-651.

[13] Ramier, J.; Gauthier, C.; Chazeau, L.; Stelandre, L.; Guy, L. J. Polym. Sci., Part B: Polym. Phys. 2007, 45 (3), 286-298.

[14] Conzatti, L.; Costa, G.; Castellano, M.; Turturro, A.; Negroni, F.M.; Gerard, J. F. Macromol. Mater. Eng. 2008, 293 (3), 178-187.

[15] Mele, P.; Marceau, S.; Brown, D.; de Puydt, Y.; Alberola, N. D. Polymer 2002, 43 (20), $5577-5586$.

[16] Stockelhuber, K. W.; Svistkov, A. S.; Pelevin, A. G.; Heinrich, G. Macromolecules 2011, 44 (11), 4366-4381. 
[17] Baeza, G. ; P.; Genix, A.-C.; Degrandcourt, C.; Petitjean, L.; Gummel, J.; Couty, M.; @berdissiee, J. Macromolecules 2013, 46 (1), 317-329.

[18] Bouty, A.; Petitjean, L.; Degrandcourt, C.; Gummel, G.; Kwasniewski, P.; Meneau, F. ; Boué, F.; Couty, M.; Jestin, J.; Macromolecules, 2014, Submitted.

[19] Termonia, Y. Polymer, 2009, 50, 1062-1066.

[20] Sung, B. J.; Chang, R.; Yethiraj, A. J. Chem. Phys., 2009, 130, 124908.

[21] Vacatello, M. Macromol. Theory Simul., 2002, 11, 757-765.

[22] Vacatello, M. Macromolecules, 2002, 35, 8191-8193.

[23] Sharaf, M. A.; Kloczkowski, A.; Sen, T. Z.; Jacob, K. I.; Mark, J. E. Eur. Polym. J., 2006, 42, 796806.

[24] Picu, R. C.; Ozmusul, M. S. J. Chem. Phys., 2003, 118, 11239-11248.

[25] Ozmusul, M. S.; Picu, R. C.; Sternstein, S. S.; Kumar, S. K. Macromolecules, 2005, 38, 4495.

[26] Nakatani, A. I.; Chen, W.; Schmidt, R. G.; Gordon, R. V.; Han, G. C. Polymer, 2001, 42, 37133722.

[27] Mackay, M. E.; Tuteja, A.; Duxbury, P. M.; Hawker, C. J.; Van Horn, B.; Guan, Z.; Chen, G.; Krishnan, R. S.; Science, 2006, 311,1740-1743.

[28] Botti, A.; Pyckhout-Hintzen, W.; Richter, D.; Urban, V.; Straube, E.; Kohlbrecher, J. Polymer, 2003, 44, 7505-7512.

[29] Sen, S.; Xie, Y.; Kumar, S. K.; Yang, H.; Bansal, A.; Ho, D. L.; Hall, L.; Hooper, J. B.; Schweizer, K. S. Phys. Rev. Lett. 2007, 98, 128302.

[30] Nusser, K.; Neueder, S.; Schneider, G. J.; Meyer, M.; Pyckhout-Hintzen, W.; Willner, L.; Radulescu, A.; Richter. D. Macromolecules 2010, 43, 98379847.

[31] Genix, A.-C. ; Tatou, M. ; Imaz, A. ; Forcada, J. ; Schweins, R. ; Grillo, I.; Oberdisse, J. Macromolecules 2012, 45 (3), 1663-1675.

[32] Jouault, N.; Dalmas, F.; Said, S.; Di-Cola, E.; Schweins, R.; Jestin, J.; Boué, F. Macromolecules 2010, 43 (23), 9881-9891. 
[33] A. Tuteja, P. M. Duxbury, M. E. Mackay, Phys. Rev. Lett. 2008, 100, 077801.

[34] Sen, S.; Xie, Y.; Bansal, A.; Yang, H.; Cho, K.; Schadler, L. S.; Kumar, S. K. Eur. Phys. J. Spec. Top. 2007, 141, 161-165.

[35] Crawford, M. K.; Smalley, R. J.; Cohen, G.; Hogan, B.; Wood, B.; Kumar, S. K.; Melnichenko, Y. B.; He, L.; Guise, W.; Hammouda. B. Phys. Rev. Lett. 2013, 110, 196001.

[36] Long, D.; Sotta, P. Macromolecules 2006, 39, 6282.

[37] Dupres, S.; Long, D.; Albouy, P. A.; Sotta, P. Macromolecules 2009, 42, 2634.

[38] Westermann, S.; Kreitschmann, M.; Pyckhout-Hintzen, W.; Richter, D.; Straube, E.; Farago, B.; Goerigk, G. Macromolecules 1999, 32, 5793.

[39] Straube, E.; Urban, V.; Pyckhout-Hintzen, W.; Richter, D.; Glinka, C. J. Phys. Rev. Lett. 1995, 74, 4464.

[40] Jouault, N.; Dalmas, F.; Said, S.; Di Cola, E.; Schweins, R.; Jestin, J.; Boué, F. Phys. Rev. E 2010, $82,031801$.

[41] Nierlich, M.; Williams, C. E.; Boue, F.; Cotton, J.-P.; Daoud, M.; Farnoux, B.; Jannink, G.; Picot, C.; Noan, M.; Wolff, C.; Rinaudo, M.; de Gennes, P. G. J. Phys. (Paris) 1979, 40, 701-704.

[42] Chevigny, C.; Gigmes, D.; Bertin, D.; Jestin, J.; Boué, F. Soft Matter 2009, 5 (19), 3741-3753.

[43] Higgins, J. S.; Benoit, H. Polymers and neutron scattering; Oxford University Press: New York, 1994.

[44] de Gennes, P. G. Scaling Concepts in Polymer Physics. Cornell University Press: Ithaca, NY, 1979. [45] Bastide, J.; Herz, J.; Boué, F. J. Phys. France 1985, 46 (11), 1967-1979.

[46] Jouault, N.; Moll, J. F.; Meng, D.; Windsor, K.; Ramcharan, S.; Kearney, C.; Kumar, S.K.; ACS Macro Lett. 2013, 2, 371-374.

[47] Jouault, N.; Lee, D.; Zhao, D.; Kumar, S.K. Advanced Materials 2014, 26 (24), 4031-4036.

[48] James, H. M.; Guth, E. The Journal of Chemical Physique 1943, 11, 455-481. 